\title{
Transient Analysis of Markovian Queueing Model with Bernoulli Schedule and Multiple Working Vacations
}

\author{
Indra \\ Associate Professor \\ Department of Statistics \& O. R., \\ Kurukshetra University Kurukshetra, \\ Haryana, INDIA
}

\author{
Renu \\ Research Scholar \\ Department of Statistics \& O. R., \\ Kurukshetra University Kurukshetra, \\ Haryana, INDIA
}

\begin{abstract}
Present study obtains the time dependent probabilities of exactly $\mathrm{i}$ arrivals and $\mathrm{j}$ departures by time $\mathrm{t}$ for $\mathrm{M} / \mathrm{M} / 1$ queueing model with Bernoulli schedule and Multiple working vacation. When a customer has just been served and other customers are present, the server accepts a customer with fix probability $\mathrm{p}$ or commences a working vacation of random duration with probability (1- p). Whenever no customers are present, after a service completion or a vacation completion, the server always takes a vacation. And the server is allowed to work at a lower rate during the vacation period. And it is shown that the transient state probabilities can be easily computed with recurrence relations. Also, some important performance measures of this model are evaluated numerically and represented graphically.
\end{abstract}

Keywords: Two-dimensional state model; Bernoulli schedule; Multiple working vacation; Laplace transform;

\section{INTRODUCTION}

We consider a queueing system where the server may not be fully available, for a period of time called vacation. These vacations of the server can be utilized for ancillary works assigned to the server. Vacation queueing systems are very important class of queues which are extensively used in the performance analysis of communication systems, computer networks, production management and many other real life situations. For example, in production system, when machine is free and have no more units to produce then it can be utilized for the inspection and preventative maintenance. Many researchers have studied the vacation queueing systems in different frameworks and elaborated many applications of such vacation models. Doshi [3] presented a methodological overview of the vacation models by giving an extensive list of references on the subject. Takagi [6] and Tian \& Zhang [12] also presented the analysis of a variety of queueing systems with vacations.

In the study of vacation models, the server is generally assumed to stop service completely during vacation. However, there are numerous situations where the server will not completely remain inactive during the vacation period rather he will render service to the queue with a different rate. In 2002, Servi and Finn [14] first studied the $\mathrm{M} / \mathrm{M} / 1$ queueing system with working vacations and provided the analysis for the Wavelengthdivision multiplexing (WDM) optimal access network using multiple wavelengths, which can be reconfigured. Subsequently, Kim, Choi et al. [8], Wu and Takagi [16] generalized the model in [9] to an $\mathrm{M} / \mathrm{G} / 1$ queue with general working vacations. Later on, Indra and Ruchi[6], Baba [1] and Banik et al. [2] concentrated on the concept of working vacations. Liu et al. [10] established the stochastic decomposition in the $\mathrm{M} / \mathrm{M} / 1$ queue with working vacations. Further, various authors studied queues with server vacations under various vacation policies including Bernoulli schedules. The classical vacation scheme with Bernoulli schedule in which the server serves the new customer with probability $\mathrm{p}$ or takes a vacation with probability (1-p) was originated and developed significantly by Keilson and Servi [7]. The advantage of the Bernoulli schedule is the existence of a control parameter $p$. By adjusting the value of $p$, we can control the congestion of the system. Various aspects of Bernoulli vacation models for single server queueing systems have been studied by Servi [3], Ramaswamy and Servi [13], Doshi [3], and Takagi [15], among several others. All of the above mentioned contributions on working vacation are confined to results describing steady-state operation only.

The study of transient solution of queueing systems taking together the above mentioned features is interesting and not much work is found in literature. But these transient solutions are quite complex, involving modified Bessel functions and worse yet an infinite series of such functions. Moreover, the classical transient results for the $\mathrm{M} / \mathrm{M} / 1$ queue provide little insight into the behavior of a queueing system through a fixed operation time $t$, but provide virtually no information on how the system has operated up until time t. To answers the questions regarding the system operation during a time period $t$, we obtain the transient solution of two-dimensional M/M/1 queueing model with Multiple working vacations and Bernoulli schedule in which the state of the system is given by (i,j), where ' $i$ ' is the number of arrivals and ' $j$ ' is the number of departures until time t. Finally, we discuss some important measures of this model, which may lead to remarkable simplification while solving the problems of similar nature. Also the transient analysis helps us to understand the behaviour of a system when the parameters are perturbed.

The rest of this paper is organized as follows. Section 2 gives a relatively formal description of the queueing model. In Section 3, we define the two-dimensional state model and derive the difference-differential equations and time dependent solution is also obtained for our model. Some special cases are discussed in Section 4. Section 5 presents the performances measures with numerical results where we provide a variety of tables for different values of the model parameters and also we have numerically verified our results in some special cases that exists in the literature. Some graphs are presented showing the effect of model parameters on some performance measures in Section 6 . 


\section{MODEL DESCRIPTION}

\subsection{Assumptions and Notations:}

- The arrivals follow a Poisson distribution with parameter $\lambda$.

- The service times are exponentially distributed with parameter $\mu_{\mathrm{B}}$ and $\mu_{\mathrm{V}}$ for busy and vacation period respectively.

- The vacation time of the service channel follows an exponential distribution with parameter $\mathrm{w}$.

- Various stochastic processes involved in the system are statiscally independent.

- Service discipline is First Come First Served(FCFS).

Initially, there are no units in the system and the server is on working vacation, i.e.

$$
\begin{aligned}
& \mathrm{P}_{0,0, \mathrm{~V}}(0)=1 \mathrm{P}_{0,0, \mathrm{~B}}(0)=0 \\
& \delta_{\mathrm{i}, \mathrm{j}}= \begin{cases}1 ; & \text { when } \mathrm{i}=\mathrm{j} \\
0 ; & \text { when } \mathrm{i} \neq \mathrm{j}\end{cases}
\end{aligned}
$$

Laplace transform of $\mathrm{F}$ ( $\mathrm{t})$ is

$$
\overline{\mathrm{F}}(\mathrm{s})=\int_{0}^{\infty} \mathrm{e}^{-\mathrm{st}} \mathrm{F}(\mathrm{t}) \mathrm{dt} \quad ; \operatorname{Re}(\mathrm{s})>0(\mathbf{2 . 2})
$$$$
\overline{\mathrm{N}}_{\mathrm{n}_{1}, \mathrm{n}_{2}, \mathrm{n}_{3}}^{\mathrm{a}, \mathrm{b}, \mathrm{s}}(\mathrm{s})=\frac{1}{(\mathrm{~s}+\mathrm{a})^{\mathrm{n}_{1}}(\mathrm{~s}+\mathrm{b})^{\mathrm{n}_{2}}(\mathrm{~s}+\mathrm{c})^{\mathrm{n}_{3}}}
$$

The Laplace Inverse of

$$
\begin{aligned}
& \frac{\mathrm{Q}(\mathrm{p})}{\mathrm{P}(\mathrm{p})} \text { is } \sum_{\mathrm{k}=1 \ell=1}^{\mathrm{n}} \sum_{\mathrm{k}}^{\mathrm{m}_{\mathrm{k}}} \frac{\mathrm{t}^{\mathrm{m}_{\mathrm{k}}-\ell} \mathrm{e}^{\mathrm{a}_{\mathrm{k}} \mathrm{t}}}{\left.\mathrm{m}_{\mathrm{k}}-\ell\right) !(\ell-1) !} \times \\
& \left.\frac{\mathrm{d}^{\ell-1}}{\mathrm{dp}^{\ell-1}} \frac{\mathrm{Q}(\mathrm{p})}{\mathrm{P}(\mathrm{p})}\left(\mathrm{p}-\mathrm{a}_{\mathrm{k}}\right)^{\mathrm{m}_{\mathrm{k}}}\right|_{\mathrm{p}=\mathrm{a}_{\mathrm{k}}} \mathrm{a}_{\mathrm{i}} \neq \mathrm{a}_{\mathrm{k}} \text { for } \mathrm{i} \neq \mathrm{k}
\end{aligned}
$$

Where,

$$
P(p)=\left(p-a_{1}\right)^{m_{1}}\left(p-a_{2}\right)^{m_{2}} \ldots\left(p-a_{n}\right)^{m_{n}}
$$

$\mathrm{Q}(\mathrm{p})$ is a polynomial of degree $<$

$$
\mathrm{m}_{1}+\mathrm{m}_{2}+\mathrm{m}_{3}+\ldots .+\mathrm{m}_{\mathrm{n}}-1
$$

$$
\begin{aligned}
& \mathrm{N}_{\mathrm{n}_{1}, \mathrm{n}_{2}, \mathrm{n}_{3}}^{\mathrm{a}, \mathrm{c}}(\mathrm{t})=\sum_{\ell=1}^{\mathrm{n}_{3}} \sum_{\mathrm{m}=1}^{\ell} \frac{\mathrm{e}^{-\mathrm{at}} \mathrm{t}^{\mathrm{n}_{3}-\ell}(-1)^{\mathrm{m}+1}+\left(\begin{array}{c}
\ell-1 \\
\mathrm{~m}-1
\end{array}\right)\left(\prod_{\mathrm{g}_{1}=0}^{\ell-\mathrm{m}-1}\left(\mathrm{n}_{1}+\mathrm{g}_{1}\right)\right)^{\delta_{\mathrm{m}, \ell}}\left(\prod_{\mathrm{g}_{2}=0}^{\mathrm{m}-2}\left(\mathrm{n}_{2}+\mathrm{g}_{2}\right)\right)^{1-\delta_{\mathrm{m}, 1}}}{(\mathrm{~b}-\mathrm{a})^{\mathrm{n}_{2}+\mathrm{m}-1}(\mathrm{c}-\mathrm{a})^{\mathrm{n}_{1}+\ell-\mathrm{m}}} \\
& +\sum_{\ell=1}^{\mathrm{n}_{2}} \sum_{\mathrm{m}=1}^{\ell} \frac{\mathrm{e}^{-\mathrm{bt}} \mathrm{t}^{\mathrm{n}_{2}-\ell}(-1)^{\mathrm{m}+1}}{\left(\mathrm{n}_{2}-\ell\right) !(\mathrm{m}-1) !} \frac{\left(\begin{array}{c}
\ell-1 \\
\mathrm{~m}-1
\end{array}\right)\left(\prod_{\mathrm{g}_{1}=0}^{\ell-\mathrm{m}-1}\left(\mathrm{n}_{1}+\mathrm{g}_{1}\right)\right)^{\delta_{\mathrm{m}, \ell}}\left(\prod_{\mathrm{g}_{2}=0}^{\mathrm{m}-2}\left(\mathrm{n}_{3}+\mathrm{g}_{2}\right)\right)^{1-\delta_{\mathrm{m}, 1}}}{(\mathrm{a}-\mathrm{b})^{\mathrm{n}_{3}+\mathrm{m}-1}(\mathrm{c}-\mathrm{b})^{\mathrm{n}_{1}+\ell-\mathrm{m}}} \\
& +\sum_{\ell=1}^{\mathrm{n}_{1}} \sum_{\mathrm{m}=1}^{\ell} \frac{\mathrm{e}^{-\mathrm{ct}} \mathrm{t}^{\mathrm{n}_{1}-\ell}(-1)^{\mathrm{m}+1}}{\left(\mathrm{n}_{1}-\ell\right) !(\mathrm{m}-1) !} \frac{\left(\begin{array}{c}
\ell-1 \\
\mathrm{~m}-1
\end{array}\right)\left(\prod_{\mathrm{g}_{1}=0}^{\ell-\mathrm{m}-1}\left(\mathrm{n}_{2}+\mathrm{g}_{1}\right)\right)^{\delta_{\mathrm{m}, \ell}}\left(\prod_{\mathrm{g}_{2}=0}^{\mathrm{m}-2}\left(\mathrm{n}_{3}+\mathrm{g}_{2}\right)\right)^{1-\delta_{\mathrm{m}, 1}}}{(\mathrm{a}-\mathrm{c})^{\mathrm{n}_{3}+\mathrm{m}-1}(\mathrm{~b}-\mathrm{c})^{\mathrm{n}_{2}+\ell-\mathrm{m}}}
\end{aligned}
$$

\section{THE TWO-DIMENSIONAL STATE MODEL \\ Define}

$\mathrm{P}_{\mathrm{i}, \mathrm{j}, \mathrm{V}}(\mathrm{t})=$ The probability that there are exactly $\mathrm{i}$ arrivals and $\mathrm{j}$ departures by time $\mathrm{t}$ and the server is on working vacation. $\quad \mathrm{j} \leq \mathrm{i}$

$\mathrm{P}_{\mathrm{i}, \mathrm{j}, \mathrm{B}}(\mathrm{t})=$ The probability that there are exactly $\mathrm{i}$ arrivals and $\mathrm{j}$ departures by tim $\mathrm{t}$ and the server is busy in relation to the queue, $\quad \mathrm{j}<\mathrm{i}$

$P_{i, j}(t)=$ The probability that there are exactly $i$ arrivals and $j$ departures by time $t$, $\mathrm{j} \leq \mathrm{i}$

3.1 The difference-differential

equations governing the system are

$\frac{d}{d t} P_{i, i, V}(t)=-\lambda P_{i, i, V}(t)+\mu_{V} P_{i, i-1, V}(t)\left(1-\delta_{i, 0}\right)$

$+\mu_{\mathrm{B}} \mathrm{P}_{\mathrm{i}, \mathrm{i}-1, \mathrm{~B}}(\mathrm{t})\left(1-\delta_{\mathrm{i}, 0}\right)$

$; \mathrm{i} \geq 0$

$$
\begin{gathered}
\frac{d}{d t} P_{i, j, V}(t)=-\left(\lambda+\mu_{V}+w\right) P_{i, j, V}(t)+\lambda P_{i-1, j, V}(t)+ \\
\mu_{V} P_{i, j-1, V}(t)\left(1-\delta_{j, 0}\right)+\mu_{B}(1-p) P_{i, j-1, B}(t)\left(1-\delta_{j, 0}\right) \\
; i>j \geq 0 \quad(3.2) \\
\frac{d}{d t} P_{i, j, B}(t)=-\left(\lambda+\mu_{B}\right) P_{i, j, B}(t)+\lambda P_{i-1, j, B}(t)+ \\
\mu_{B} p P_{i, j-1, B}(t)\left(1-\delta_{j, 0}\right)+w_{i, j, V}(t) ; i>j \geq 0 \\
P_{i, j}(t)=P_{i, j, V}(t)+P_{i, j, B}(t)\left(1-\delta_{i, j}\right) \\
; i \geq j \geq 0 \quad(3.4)
\end{gathered}
$$

\section{Solution of the Problem}

Taking the Laplace transform of equations (3.1) to (3.3) along with (2.1) and solving recursively, we have

$$
\overline{\mathrm{P}}_{0,0, \mathrm{~V}}(\mathrm{~s})=\frac{1}{\mathrm{~s}+\lambda}
$$

(3.1) 


$$
\begin{aligned}
& \bar{P}_{i, 0, V}(s)=\left(\frac{\lambda}{s+\lambda+\mu_{V}+w}\right)^{i} \frac{1}{(s+\lambda)} ; i>0(3.6) \\
& \bar{P}_{i, 0, B}(s)=\sum_{k=0}^{i-1} \lambda^{i} w \bar{N}_{1, i-k, k+1}(s) ; i>0 \\
& \bar{P}_{i, j, V}(s)=\sum_{k=1}^{i-j+1} \lambda^{i-j} \mu_{V} \bar{N}_{\delta_{k, 1},\left(i-j-k+2-\delta_{k, 1}\right.}(s) \\
& \bar{P}_{j+k-1, j-1, V}(s)+\sum_{k=1}^{i-j+1} \lambda^{i-j} \mu_{B}(1-p)^{\delta_{k, 1}} \\
& \bar{N}_{\delta_{k, 1},\left(i-j-k+2-\delta_{k, 1}\right)}(s) \cdot \bar{P}_{j+k-1, j-1, B}(s) ; i \geq j>0(3.8) \\
& \bar{P}_{i, j, B}(s)=\sum_{k=1}^{i-j} \frac{\lambda \lambda^{i-j-k} w}{\left(s+\lambda+\mu_{B}\right)^{i-j-k+1}} \bar{P}_{j+k, j, V}(s) \\
& +\sum_{k=1}^{i-j} \frac{\lambda \lambda^{i-j-k} \mu_{B} p}{\left(s+\lambda+\mu_{B}\right)^{i-j-k+1} \bar{P}_{j+k, j-1, B}(s)}
\end{aligned}
$$

; $\mathrm{i}>\mathrm{j}>\mathbf{0}$ (3.9)

Taking the Laplace Inverse transform of equations (3.5) to (3.9), we have

$$
\begin{aligned}
& \mathrm{P}_{0,0, \mathrm{~V}}(\mathrm{t})=\mathrm{e}^{-\lambda \mathrm{t}} \\
& P_{i, 0, V}(t)=\lambda^{i} e^{-\lambda t} \times \\
& \left\{\frac{1}{\left(\mu_{V}+w\right)^{i}}-e^{-\left(\mu_{V}+w\right) t} \sum_{k=0}^{i-1} \frac{t^{k}}{k !} \cdot \frac{1}{\left(\mu_{V}+w\right)^{i-k}}\right\} \\
& \text {;i>0 (3.11) } \\
& \mathrm{P}_{\mathrm{i}, 0, \mathrm{~B}}(\mathrm{t})=\sum_{\mathrm{k}=0}^{\mathrm{i}-1} \lambda^{\mathrm{i}} \mathrm{w} \mathrm{N}_{1, \mathrm{i}-\mathrm{k}, \mathrm{k}+1}(\mathrm{t}) \quad ; \mathrm{i}>0(\mathbf{3 . 1 2}) \\
& P_{i, j, V}(t)=\sum_{k=1}^{i-j+1} \lambda^{i-j} \mu_{V} N_{\delta_{k, 1},\left(i-j-k+2-\delta_{k, 1}\right)}(t) \\
& * \mathrm{P}_{\mathrm{j}+\mathrm{k}-1, \mathrm{j}-1, \mathrm{~V}}(\mathrm{t})+\sum_{\mathrm{k}=1}^{\mathrm{i}-\mathrm{j}+1} \lambda^{\mathrm{i}-\mathrm{j}} \mu_{\mathrm{B}}(1-\mathrm{p})^{\delta_{\mathrm{k}, 1}} \\
& \mathrm{~N}_{\delta_{\mathrm{k}, 1},\left(\mathrm{i}-\mathrm{j}-\mathrm{k}+2-\delta_{\mathrm{k}, 1}\right)}(\mathrm{t}) * \mathrm{P}_{\mathrm{j}+\mathrm{k}-1, \mathrm{j}-1, \mathrm{~B}}(\mathrm{t}) \\
& ; \mathrm{i} \geq \mathrm{j}>0 \text { (3.13) } \\
& P_{i, j, B}(t)=\sum_{k=1}^{i-j} \lambda^{i-j-k} w e^{-\left(\mu_{B}+\lambda\right) t} \frac{t^{i-j-k}}{(i-j-k) !} \\
& * P_{j+k, j, V}(t)+\sum_{k=1}^{i-j} \frac{t^{i-j-j-k} \mu_{B} p e^{-\left(\mu_{B}+\lambda\right) t}}{(i-j-k) !} \quad * P_{j+k, j-1, B}(t) \\
& \text {;i }>\mathrm{j}>0 \quad \text { (3.14) }
\end{aligned}
$$

\section{SPECIAL CASES}

4.1 When server takes the vacation only, i.e. byletting $\mu_{\mathrm{V}}=0$ and $\mu_{\mathrm{B}}=\mu$, obtained results agree with the results of Indra \& Renu[5].

4.2 By substituting $p=1$ in eqns. (3.1) to (3.3), the results of the above described model coincides with results of Indra \& Ruchi[6].

4.3 When server is on vacation only, i.e. $\mu_{\mathrm{v}}=0$ and $\mu_{\mathrm{B}}=\mu$ and $\mathrm{p}=1$ in eqns. (3.1) to (3.3), then above described model reduces to exhaustive service discipline and obtained results coincide with results of Indra[4].

4.4 Along with the case-4.3, when the server is instantaneously available i.e. no discipline of vacation. Letting $\mathrm{W} \rightarrow \infty$ in eqns. (3.1) to (3.3), we have

$$
\begin{gathered}
P_{0,0}(t)=P_{0,0, V}(t)=e^{-\lambda t} \\
P_{i, j}(t)=\left(\frac{\lambda}{\mu}\right)^{i} \frac{(\mu t)^{j} e^{-\lambda t}}{i !} \sum_{K=0}^{j} \frac{(i-k)}{k !} \\
\sum_{m=0}^{j-k}\left(\frac{(-1)^{m}(m+i+k) !}{m !(j-k-m) !(\mu t)^{m+k}}\right)\left(1-e^{-\mu t} \sum_{r=0}^{m+i+k-1} \frac{(\mu t)^{r}}{r !}\right) \text { Then }
\end{gathered}
$$

$; \mathrm{i}>\mathrm{j} \geq 0$

results coincide with eqn. (10) of Pegden and Rosenshine [12].

\section{PERFORMANCES MEASURES OF THE MODEL}

5.1 The Laplace transform $\overline{\mathrm{P}}_{\mathrm{i} \bullet}(\mathrm{s})$ of the probability $\mathrm{P}_{\mathrm{i} \bullet}(\mathrm{t})$ that exactly $\mathrm{i}$ units arrive by time $\mathrm{t}$ is;

$$
\overline{\mathrm{P}}_{\mathrm{i} \bullet}(\mathrm{s})=\sum_{\mathrm{j}=0}^{\mathrm{i}} \overline{\mathrm{P}}_{\mathrm{i}, \mathrm{j}}(\mathrm{s})=\frac{\lambda^{\mathrm{i}}}{(\mathrm{s}+\lambda)^{\mathrm{i}+1}} ; \mathbf{i}>\mathbf{0} \text { (5.1) }
$$

And its Inverse Laplace transform is

$P_{i \bullet}(t)=\sum_{j=0}^{i} P_{i, j}(t)=\frac{(\lambda t)^{i} e^{-\lambda t}}{i !}$

The arrivals follow a Poisson distribution as the probability of the total number of arrivals is not affected by the vacation times of the server.

And the numerical results for the probabilities of exact number of arrivals when the server is busy i.e. $\sum_{j=0}^{i} P_{i, j, B}(t)$,

when the server is on working vacation i.e. $\sum_{j=0}^{i} P_{i, j, V}(t)$ and by a given time $t$ i.e. $\sum_{j=0}^{i} P_{i, j}(t)$, are computed for different sets of parameter and are summarized in Table-1. Table-1 is based on the relationship (4.2) where $\mathrm{P}_{\mathrm{i}, \mathrm{j}}(\mathrm{t})$ is defined in equation (3.4). 
Table-1 (for exactly i customers have been arrived by time t)

\begin{tabular}{|c|c|c|c|c|c|c|c|c|c|}
\hline$\lambda$ & $\mu_{B}$ & $\mu_{V}$ & $\mathbf{W}$ & $\mathbf{i}$ & $\mathbf{t}$ & $\frac{\mathrm{e}^{-\lambda \mathrm{t}}(\lambda \mathrm{t})^{\mathrm{i}}}{\mathrm{i}}$ & $\sum_{\mathrm{j}=0}^{\mathrm{i}} \mathrm{P}_{\mathrm{i}, \mathrm{j}, \mathrm{V}}(\mathrm{t})$ & $\sum_{\mathrm{j}=0}^{\mathrm{i}} \mathrm{P}_{\mathrm{i}, \mathrm{j}, \mathrm{B}}(\mathrm{t})$ & $\sum_{\mathrm{j}=0}^{\mathrm{i}} \mathrm{P}_{\mathrm{i}, \mathrm{j}}(\mathrm{t})$ \\
\hline 1 & 2 & 1 & 1 & 1 & 3 & 0.149361 & 0.1371304051 & 0.0122307999 & 0.1493612051 \\
\hline 1 & 2 & 1 & 1 & 3 & 3 & 0.224042 & 0.1679053944 & 0.0561364132 & 0.2240418076 \\
\hline 1 & 2 & 1 & 1 & 5 & 3 & 0.100819 & 0.0634524934 & 0.0373663200 & 0.1008188134 \\
\hline 2 & 3 & 2 & 1 & 1 & 3 & 0.014873 & 0.0143223590 & 0.0005501540 & 0.0148725130 \\
\hline 2 & 3 & 2 & 1 & 3 & 3 & 0.089235 & 0.0783402539 & 0.0108948244 & 0.0892350783 \\
\hline 3 & 4 & 3 & 1 & 1 & 3 & 0.001111 & 0.0010875507 & 0.0000231374 & 0.0011106882 \\
\hline 3 & 4 & 3 & 1 & 3 & 3 & 0.014994 & 0.0139660297 & 0.0010282614 & 0.0149942911 \\
\hline 3 & 4 & 3 & 1 & 5 & 3 & 0.060727 & 0.05327103033 & 0.0074558490 & 0.0607268793 \\
\hline
\end{tabular}

The last column of Table - 1 shows complete agreement with the Table - I of Pegden \& Rosenshine[12]

5.2 The Laplace transform of mean number of arrivals

bytime $\mathrm{t}$ is $\sum_{\mathrm{i}=0}^{\infty} \mathrm{i} \overline{\mathrm{P}}_{\mathrm{i} \bullet}(\mathrm{s})=\frac{\lambda}{\mathrm{s}^{2}}$

And its Inverse Laplace transform is

$$
\sum_{\mathrm{i}=0}^{\infty} \mathrm{i} \mathrm{P}_{\mathrm{i} \bullet}(\mathrm{t})=\lambda \mathrm{t}
$$

5.3 From (3.5)-(3.9), it is seen that $\sum_{i=0}^{\infty} \sum_{j=0}^{i}\left\{\overline{\mathrm{P}}_{\mathrm{i}, \mathrm{j}, \mathrm{V}}(\mathrm{s})+\overline{\mathrm{P}}_{\mathrm{i}, \mathrm{j}, \mathrm{B}}(\mathrm{s})\left(1-\delta_{\mathrm{i}, \mathrm{j}}\right)\right\}=\frac{1}{\mathrm{~s}}$

and hence $\sum_{\mathrm{i}=0}^{\infty} \sum_{\mathrm{j}=0}^{\mathrm{i}}\left\{\mathrm{P}_{\mathrm{i}, \mathrm{j}, \mathrm{V}}(\mathrm{t})+\mathrm{P}_{\mathrm{i}, \mathrm{j}, \mathrm{B}}(\mathrm{t})\left(1-\delta_{\mathrm{i}, \mathrm{j}}\right)\right\}=1$

\section{a verification.}

5.4 The numerical results for the probabilities that exactly $\mathrm{j}$ number of customers have been served by time $\mathrm{t}$ when the server is on working vacation i.e. $\sum_{i=j}^{\infty} P_{i, j}, V(t)$, when the server is busy i.e. $\sum_{i=j}^{\infty} P_{i, j, B}(t)$ are computed for different sets of parameters $\left(\lambda=2, \mu_{\mathrm{V}}=2, \mu_{\mathrm{B}}=3, \mathrm{w}=2, \mathrm{t}=2\right.$, $\mathrm{p}=0.4,0.6,0.8)$ and are summarized in Table -2 . Table- 2 is based on the relationship $\mathrm{P}_{\bullet j}(\mathrm{t})=\sum_{\mathrm{i}=\mathrm{j}}^{\infty} \mathrm{P}_{\mathrm{i}, \mathrm{j}}(\mathrm{t})$, where $P_{i, j}(t)$ is defined in equation (3.4). By adjusting the value of $\mathrm{p}$, we can control the congestion of the system. And from the numerical results it is obvious that as $p$ increases the probability of departures increases when the server is busy.
Table-2(for exactly $\mathbf{j}$ customers have been served by time t)

\begin{tabular}{|c|c|c|c|c|}
\hline $\mathbf{j}$ & $\mathbf{p}$ & $\sum_{\mathrm{i}=\mathrm{j}}^{\infty} \mathrm{P}_{\mathrm{i}, \mathrm{j}, \mathrm{V}}(\mathrm{t})$ & $\sum_{\mathrm{i}=\mathrm{j}}^{\infty} \mathrm{P}_{\mathrm{i}, \mathrm{j}, \mathrm{B}}(\mathrm{t})$ & $\sum_{\mathrm{i}=\mathrm{j}}^{\infty} \mathrm{P}_{\mathrm{i}, \mathrm{j}}(\mathrm{t})$ \\
\hline 1 & 0.4 & 0.116983064 & 0.062523573 & 0.179506637 \\
\hline 2 & 0.4 & 0.171093585 & 0.068928161 & 0.240021747 \\
\hline 3 & 0.4 & 0.146731916 & 0.041591247 & 0.188323163 \\
\hline 4 & 0.4 & 0.079261543 & 0.012528579 & 0.091790123 \\
\hline 1 & 0.6 & 0.113007696 & 0.064811191 & 0.177818887 \\
\hline 2 & 0.6 & 0.163629539 & 0.074463751 & 0.238093290 \\
\hline 3 & 0.6 & 0.141784290 & 0.047031882 & 0.188816172 \\
\hline 4 & 0.6 & 0.078879825 & 0.014873511 & 0.093753337 \\
\hline 1 & 0.8 & 0.10903232 & 0.067098809 & 0.176131137 \\
\hline
\end{tabular}

(Variation for different values of $p$ )

5.5 The probability of exactly $n$ customers in the system at time $t$, denoted by $P_{n}(t)$ can be expressed in terms of $\mathrm{P}_{\mathrm{i}, \mathrm{j}}(\mathrm{t})$.

(i) Customers during busy period, i.e. 
$P_{n, B}(t)=\sum_{\mathrm{j}=0}^{\infty} \mathrm{P}_{\mathrm{j}+\mathrm{n}, \mathrm{j}, \mathrm{B}}(\mathrm{t})$

(ii) Customers during working vacation period, i.e $P_{n, V}(t)=\sum_{\mathrm{j}=0}^{\infty} \mathrm{P}_{\mathrm{j}+\mathrm{n}, \mathrm{j}, \mathrm{V}}(\mathrm{t})$.

Table-3 is based on the relationship

$\mathrm{P}_{n}(\mathrm{t})=\sum_{j=0}^{\infty} \mathrm{P}_{\mathrm{j}+\mathrm{n}, \mathrm{j}}(\mathrm{t})$, Where

$\mathrm{P}_{n}(\mathrm{t})=P_{n, B}(t)+P_{n, V}(t)$

$\mathrm{P}_{\mathrm{n}, \mathrm{B}}(\mathrm{t}), \mathrm{P}_{\mathrm{n}, \mathrm{V}}(\mathrm{t})$ and $\mathrm{P}_{\mathrm{n}}(\mathrm{t})$, for different values of $\operatorname{parameters}\left(\lambda=2, \mu_{\mathrm{V}}=2, \mu_{\mathrm{B}}=3, \mathrm{w}=2, \mathrm{p}=0.4\right)$ and for different values of $\mathrm{t}$.

\section{Table-3(fexactly $\mathbf{n}$ customers in the system)}

\begin{tabular}{|c|c|c|c|c|}
\hline $\mathrm{t}$ & $\mathrm{n}$ & $\mathrm{P}_{\mathrm{n}, \mathrm{V}}(\mathrm{t})$ & $\mathrm{P}_{\mathrm{n}, \mathrm{B}}(\mathrm{t})$ & $\mathrm{P}_{\mathrm{n}}(\mathrm{t})$ \\
\hline 1 & 1 & 0.19889230 & 0.09766584 & 0.296558 \\
\hline 1 & 3 & 0.03336610 & 0.03990509 & 0.073271 \\
\hline 1 & 5 & 0.00156973 & 0.00344526 & 0.005014 \\
\hline 2 & 1 & 0.15333946 & 0.08385372 & 0.237193 \\
\hline 2 & 3 & 0.02463712 & 0.03886233 & 0.063499 \\
\hline 2 & 5 & 0.00051533 & 0.00241812 & 0.002933 \\
\hline 3 & 1 & 0.08546977 & 0.04968967 & 0.135159 \\
\hline 3 & 3 & 0.00782435 & 0.01448247 & 0.022306 \\
\hline 3 & 5 & 0.00007687 & 0.00046321 & 0.000540 \\
\hline 4 & 1 & 0.03395907 & 0.02048603 & 0.054445 \\
\hline 4 & 3 & 0.00179490 & 0.00364575 & 0.005440 \\
\hline 4 & 5 & 0.00001047 & 0.00006672 & 0.000077 \\
\hline 5 & 1 & 0.01077901 & 0.00663863 & 0.017417 \\
\hline 5 & 3 & 0.00036158 & 0.00077622 & 0.001137 \\
\hline 5 & 5 & 0.00000141 & 0.00000910 & 0.000010 \\
\hline
\end{tabular}

5.6 The system utilization and the system working vacation time i.e. the fraction of time the server is busy \& the fraction of time the server is on working vacation until time $t$ can also be expressed in terms of $\mathrm{P}_{i, j}(t)$.

Thus the server's utilization time is

$U(t)=\sum_{i=0 j=0}^{\infty} \sum_{i, j, B}^{i} P_{1}(t)$ And the server's vacation time is

$V(t)=\sum_{i=0}^{\infty} \sum_{j=0}^{i} P_{i, j, V}(t)$. Here, the Server's utilization time and Working vacation time are evaluatedfor $\lambda=2, \mu_{\mathrm{V}}=2, \mu_{\mathrm{B}}=3, \mathrm{w}=1, \mathrm{p}=0.2$ and for different values of $\mathrm{t}$.

\section{GRAPHICAL REPRESENTATION}
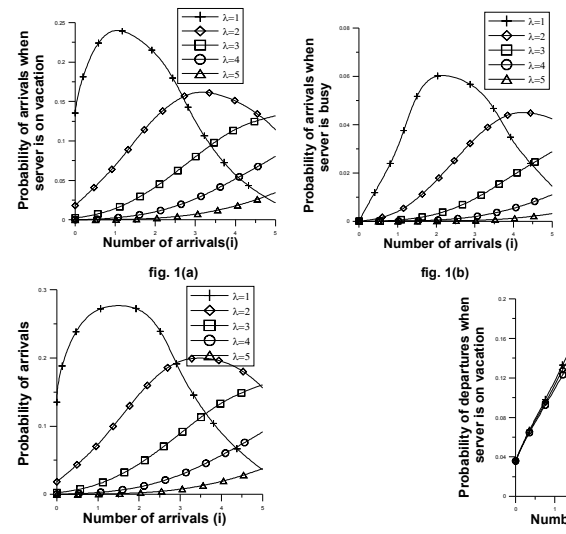

fig. 1 (b)

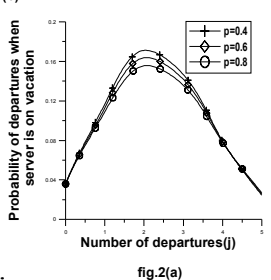

fig. 1(c)
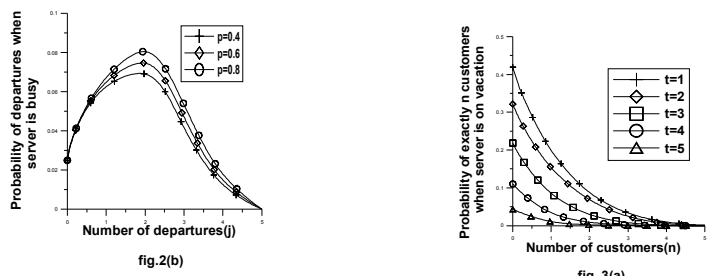

fig.2(b)

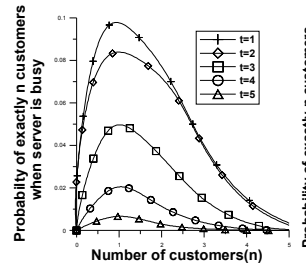

fig. 3(b)

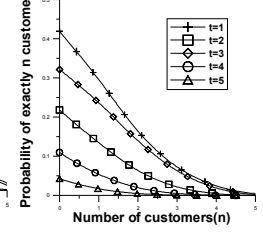

fig. 3(c)

In figures 1(a)-1(c), the graphical representation of $P_{i, \bullet}(t)$ with the variation of arrival rate $\lambda$ has been shown. In figs. 2(a)-2(b), changes of $P_{\bullet j}(t)$ with the variation of $p$ has been shown. In figs. 3(a)-3(c), variation of $P_{n, B}(t), P_{n, V}(t)$ and $P_{n}(t)$ with the different values of $t$ has been shown.
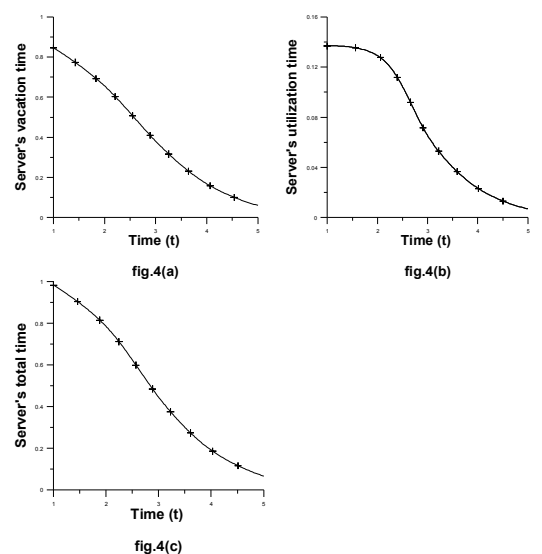

In figs. 4(a)-4(b), the graphical representation of Server's Utilization time and Server's Vacation time has been shown. 


\section{CONCLUSION}

From Two-dimensional state queueing model, factors should be well understood and quantified. This model applies to manufacturing processes that exhibit uninterruptible maintenance tasks such as 7 manufacturing system. Finally, the numerical analysis clearly demonstrates the meaningful impact of the server vacations on the system performances.

\section{REFERENCES}

[1]. Baba, Y., (2005), Analysis of a GI/M/1 queue with multiple working vacations. Oper. Res. Lett. 33, 201-209.

[2] Banik, A.D., Gupta, U.C., Pathak, S.S. (2007), On the $\mathrm{GI} / \mathrm{M} / 1 / \mathrm{N}$ queue with multiple working vacations analytic analysis and computation Appl. Math. Modell. 31(9), 1701-1710.

[3] Doshi, B.T. (1986), Queueing systems with vacations- a survey, queueing systems, Vol. 1, p.p.29-66.

[4] Indra, (1994), Some two-state single server queueing models with vacation or latest arrival run, Ph.D. thesis, Kurukshetra University, Kurukshetra.

[5] Indra and Renu, (2009), Utilization of idle time of $\mathrm{M} / \mathrm{M} / 1$ queueing model with Bernoulli Schedule, Operations and Management sciences 2010, pp. 271285.

[6] Indra and Ruchi, (2009), Transient analysis of twodimensional $\mathrm{M} / \mathrm{M} / 1$ queueing system with working vacations, JMASS, Vol. 5, No. 2, pp. 110-128.
[7] Keilson J. and Servi, L.D., (1987), Dynamics of the M/G/1 vacation model, Opns. Res., Vol. 35, No. 4, p.p.575-582.

[8]. Kim, J.D., Choi, D.W., Chae, K.C, (2003), Analysis of queue-length distribution of the $\mathrm{M} / \mathrm{G} / 1$ queue with working vacations. In Hawaii International Conference on Statistics and Related Fields.

[9] L.D. Servi (1986), Average delay approximation of /G/1 cyclic service queue with Bernoulli schedules, IEEE Selected Area of Communication 4, 813-820.

[10]Liu, W., Xu, X., Tian, N.(2007): Stochastic decompositions in the $\mathrm{M} / \mathrm{M} / 1$ queue with working vacations. Oper. Res. Lett. 35, 595-600.

[11] N. Tian and Z.G. Zhang(2006), Vacation Queueing Models: Theory and Applicati ons, Springer, New York.

[12]Pegden, C.D. and Rosenshine, M. (1982), Some new results for the $M / M / 1$ queue, Mgt. Sc.,Vol. 28, 821-828.

[13] R. Ramaswami, L.D. Servi(1988), The busy period of the $\mathrm{M} / \mathrm{G} / 1$ vacation model with a Bernoulli schedule, Stochastic Models 4, 507-521.

[14] Servi, L.D. and Finn, S.G., (2002), M/M/1 queues with working vacations $(\mathrm{M} / \mathrm{M} / 1 / \mathrm{WV})$, Performance Evaluation, Vol. 50, pp 41-52.

[15] Takagi, H. (1991). Queueing Analysis: A Foundation of Performance evaluation, vacation and priority systems, Part 1, North-Holland, Amsterdam.

[16] Wu, D., Takagi, H., (2006), M/G/1 queue with multiple working vacations. Perform. Eval. 63(7), 654-681. 